\title{
Translation, adaptation and pilot testing of the Pictorial Fit-Frail Scale (PFFS) for use in Malaysia - The PFFS-Malay version (PFFS-M)
}

\author{
Sally Suriani Ahip, Sazlina Shariff-Ghazali, Sabrina Lukas, Azah Abdul Samad, Ummu \\ Kalsum Mustapha, Olga Theou, Renuka Visvanathan \\ Ahip SS, Shariff-Ghazali S, Lukas S, et al. Translation, adaptation and pilot testing of the Pictorial Fit-Frail Scale (PFFS) for use in Malaysia- \\ The PFFS-Malay version (PFFS-M). Malays Fam Physician. 2021;16(2);27-36. https://doi.org/10.51866/oa1036
}

Keywords:

Frailty, screening, Malaysia

\section{Authors:}

Sally Suriani Ahip

(Corresponding author)

MBBS, MMed

Kota Samarahan Health Clinic

Sarawak, Malaysia

Email: sally.ahip@gmail.com

\section{Sazlina Shariff Ghazali \\ MBBS, MMed, PhD \\ Faculty of Medicine and Health \\ Sciences, Universiti Putra Malaysia \\ Malaysia}

Malaysian Research Institute on Ageing (MyAgeingTM), Universiti Putra Malaysia, Malaysia

\section{Sabrina Lukas}

MBBS, MMed

Universiti Malaysia Sarawak

Malaysia

\section{Azah Abdul Samad}

MBBS, MMed

Shah Alam Section 7 Health Clinic

Selangor, Malaysia

\section{Ummu Kalsum Mustapha MBBS, MMed \\ Dengkil Health Clinic, Selangor Malaysia}

\section{Olga Theou}

PhD

Physiotherapy and Medicine,

Dalhousie University, Halifax, Canada

\begin{abstract}
Background: Frailty is an important health issue in an aging population; it is a state of vulnerability that renders the elderly susceptible to adverse health outcomes, including disability, hospitalization, long-term care admission and death. Early frailty stages are recognizable through screening and are reversible with targeted interventions. To date, however, there is no screening tool for use in Malaysia. The English Pictorial Fit-Frail Scale (PFFS) is a visual tool that assesses a person's fitness-frailty level in 14 health domains, with higher scores indicating higher frailty. Objective: The aim was to translate and adapt the English PFFS for use in Malaysian clinical settings.

Methods: The original English PFFS underwent forward and backward-translation by two bilingual translators to and from the Malay language. A finalized version, the PFFS-Malay (PFFS-M), was formed after expert reviewers' consensus and was pilot tested with 20 patients, 20 caregivers, 16 healthcare assistants, 17 nurses and 22 doctors. Score agreement between patients and their caregivers and among healthcare professionals were assessed. All participants rated their understanding of the scale using the feasibility survey forms.

Results: A total of 95 participants were included. There were high percentages of scoring agreements among all participants on the scale (66.7\% to 98.9\%). Overall feedback from all respondents were positive and supported the face validity of the PFFS-M.

Conclusion: The PFFS-M reflects an accurate translation for the Malaysian population. The scale is usable and feasible and has face validity. Reliability and predictive validity assessments of the PFFS-M are currently underway.
\end{abstract}

\section{Background}

Of the current global population, about 461 million people are aged 65 years and older, and this statistic is estimated to increase to 2 billion by $2050 .{ }^{1}$ In Malaysia, the elderly, defined as those who are 60 years and above, have increased from $5.7 \%$ of the total population in 1980 to $6.2 \%$ in $2000 .{ }^{2}$ Further, it is projected that, by 2040 , the Malaysian population aged 60 years and above will increase to $17.6 \%$ of the projected population of 40 million. ${ }^{3}$ Population aging, as noted both in Malaysia and worldwide, is attributable to successful global improvements in healthcare, reduced mortality, improved socioeconomic and education status, and declining fertility rates. ${ }^{4}$ However, as the average age of a population climbs, there will be a greater need to manage geriatric conditions; Malaysia must therefore develop and capitalize upon effective healthcare models to treat aging-related issues such as frailty, thus providing older citizens with improved odds of aging healthfully.

Frailty is a state of vulnerability that is associated with increased risk of poor health outcomes such as falls, disability, long-term care and death..$^{5-7}$ Frailty can be recognized early when screening strategies are in place to allow for targeted interventions focused on addressing risk factors and reversing frailty. ${ }^{6}$ Early detection of frailty, followed by timely intervention in primary care, has the potential to improve wellbeing among the elderly. Several studies have reported the effectiveness of frailty screening and subsequent, effective general practice care in preventing functional decline. ${ }^{8,9}$ A stepwise identification of older persons at risk of adverse outcomes, followed by the provision of longitudinal personalized 


\author{
Renuka Visvanathan \\ MBBS, FRACP, MBA, PhD \\ Aged and Extended Care Services \\ The Queen Elizabeth Hospital Central \\ Adelaide Local Health Network and \\ The University of Adelaide, Adelaide \\ Australia
}

care, is likely better than reactive and fragmented care for this population.

Malaysia has a two-tiered healthcare system: a government-led and funded public sector that caters to the bulk of the Malaysian population (approximately 65\%) in combination with a fast-growing private sector. ${ }^{10,11}$ The Ministry of Health, Malaysia has developed an extensive network of public primary care centres (2871 facilities) that continue to expand across both urban and rural areas throughout the country. ${ }^{10,11}$ The urban health clinics provide a wide range of comprehensive, multidisciplinary services for all age groups, including elderly health programs led by family medicine specialists, medical officers or medical assistants. ${ }^{10,11}$ However, rural and mobile clinics provide basic curative services and are usually staffed by medical assistants or nurses and healthcare assistants with regular, weekly to monthly visits by doctors. ${ }^{10,11}$ Therefore, Malaysian primary care settings require screening instruments suitable for use among healthcare workers with varying skill sets across all primary care centres, and this paradigm is both feasible for busy clinic settings as well as suitable for the multiethnic Malaysian population, in which educational status is variable.

The Pictorial Fit-Frail Scale (PFFS) is an image-based frailty screening tool recently developed by the Division of Geriatric Medicine at Dalhousie University and Nova Scotia Health Authority in Canada. ${ }^{12}$ The PFFS assesses people's health state on 14 health domains, including mobility, function, cognition, social support, affect, medication, incontinence, vision, hearing, balance and aggression. ${ }^{12}$ Each domain includes 3-6 levels that represent the quality of an individual's health state. Within each domain, the assessor selects the image that best represents the health status of the patient. Every domain tested in the tool is scored from 0 , which represents a level of least or no impairment, and increasing scores indicate a worsening health state or a higher level of impairment. The PFFS total scores are calculated by summing the scores from each domain. The sum of scores from all 14 domains ranges from 0 to 43 , with higher scores indicating increased frailty. A Frailty Index (FI) for the PFFS is constructed by dividing the total PFFS score by 43 , the maximum score for this scale.

The PFFS is brief, practical and easy to administer by patients, caregivers and healthcare professionals. ${ }^{12-14}$ On average, the time taken to complete the scale by patients and caregivers is less than 5 minutes, and for healthcare professionals, the time is less than 2 minutes. ${ }^{13,14}$ Test-retest reliability for patients and healthcare professionals have been good, with intraclass correlation coefficients (ICCs) ranging between 0.78 and $0.88 .^{13,14}$ Good inter-rater reliability for patients, caregivers and healthcare professionals has also been reported, with ICCs between 0.63 and $0.83 .{ }^{13,14}$ Pearson correlation between the PFFS and an FI based on the Comprehensive Geriatric Assessment has been reported as high and statistically significant $(r=0.64, p<0.001) . .^{13,14}$

The PFFS has been designed to be sensitive to cultural differences, and because of the linguistic diversity of the Malaysian population, it was hypothesized that the tool would have clinical utility within the Malaysian primary care setting. To date, the PFFS has not been validated in Asia. Therefore, the aim of this pilot study was to develop a Malay-language version, the PFFS-M, for use in Malaysia and to pilot the translated tool in a sample of patients, caregivers and healthcare professionals to support refinement. Findings from this study may have applicability to healthcare settings in other countries and regions of Asia.

\section{Methods \\ Developing the PFFS-M}

The permission to translate the original English-language PFFS was obtained from the Canadian team that developed the tool. ${ }^{12}$ The PFFS was translated into Malay, the official and national language of Malaysia, to produce the PFFS-M. The translation process included forward (Step 1) and backward (Step 2) translations by two bilingual translators, as described below and illustrated in Figure 1 . The PFFS-M (Step 3) was finalized following discussions with an expert panel to achieve consensus.

\section{Step 1 - Forward Translation:}

Two native speakers of the Malay language who were bilingual translated the PFFS into Malay. Each prepared a Malay translation of the tool (Translations 1 and Translation 2), discussed both versions with the principal investigator and achieved a consensus for the initial PFFS-M (the PFFS-M Consensus).

Step 2 - Backward Translation:

Next, two native speakers of the Malay 
language who were bilingual translated the PFFS-M Consensus back to English without exposure to the original PFFS. Each independently submitted to the expert committee their version (Back-translations 1 and 2).

\section{Step 3 - Expert Consensus:}

An expert committee consisting of the principal investigator (a family medicine specialist with special interest in geriatric medicine), two bilingual family medicine specialists, one geriatrician, one occupational therapist, one physiotherapist and the original developer of the PFFS reviewed all translations and reached a consensus after discussing all versions, sentence by sentence, for accuracy of the translation, comprehensibility of the instructions and cultural relevance for application within the Malaysian setting.16 Critical decisions and minor adjustments were made to achieve semantic and conceptual equivalence. A finalized version was developed (PFFS-M) for pilot testing.
Step 1:

Forward

Translation

Step 2:

Backward

Translation

Step 3:

Committee

Review
- Two bilingual translators independently translated the original English PFFS into Malay

- A consensus was reached after discussion among both translators and the principal investigator

- The initial PFFS-M Consensus was formed

- Two other bilingual translators independently translated the PFFS-M Consensus into English

- Both back-translated versions were submitted to the expert committee for review

- The expert committee consisted the principal investigator, a geriatrician, two family medicine specialists, a physiotherapist, an occupational therapist, and the developer of the PFFS

- All translations were reviewed

- A consensus was reached after discussion about translation discrepancies

- The Malay-language PFFS (PFFS-M) was finalized

Figure 1. The PFFS Translation Process

\section{Pilot and Feasibility Testing}

The PFFS-M was pilot-tested among patients, caregivers and healthcare professionals, including healthcare assistants, nurses and doctors from four public primary healthcare clinics (two urban and two rural clinics) in two states (Sarawak and Selangor) in Malaysia. When patients were unable to complete the PFFS-M, their caregivers or the healthcare professionals assisted.

Medical officers who had practiced for at least 3 years, nurses who had practiced for at least 4 years and level 2 healthcare assistants who had undergone basic vital signs and clinical assessments training were recruited via the universal sampling method. Patients were eligible for enrolment if they were 60 years and above, were able to converse in Malay and did not have severe visual impairments. Accompanying caregivers were also invited to the study. Every third patient who attended the clinic with their caregiver for a routine followup was approached and invited to participate in the pilot study until a sample of 20 patients and their caregivers was reached.

Patients and their caregivers were required to complete the PFFS-M (Figure 2) independently, for themselves (i.e., by the patient) or based on the health of the person they are caring for (i.e., by the caregiver). Age, gender and self-rated health (or carer rating of patient health) were collected as part of the sociodemographic form.

Healthcare professionals were required to complete all domains in the PFFS-M based on a clinical vignette of a typical presentation to primary care: an older woman with geriatric syndromes. Two family medicine specialists translated into Malay and adapted for the 
Malaysian primary care setting the same case scenario that was used in Canada. ${ }^{13}$ The clinical scenario was changed to one in which an older woman presented to the primary care clinic with her daughter as opposed to participating in an assessment at home following an ambulance call; otherwise, the clinical features of the older woman were the same. The principal investigator was present with the patient and carer throughout completion of the scale to assist as required.

All participants completed the acceptability questionnaire, which included a 6-point Likert scale that indicated the degree of agreement, with a score of 0 indicating agreement
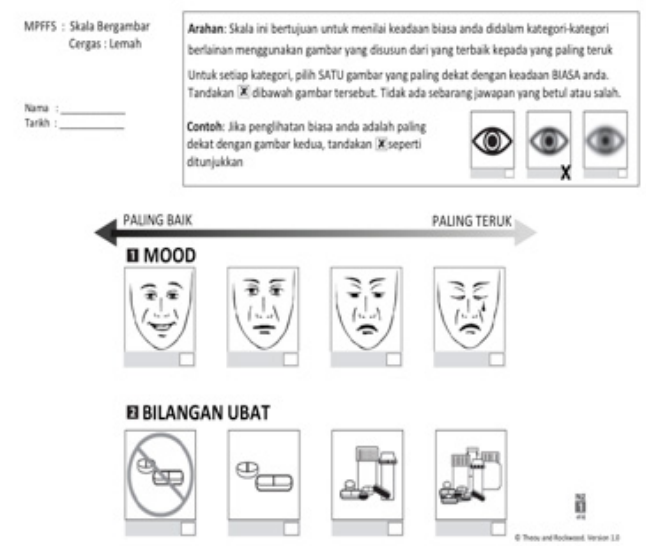

and a score of 5 indicating disagreement. Questions related to clarity of instructions, appropriateness of font and picture sizes, understanding of pictures in the scale and appropriateness of domain titles were included in the questionnaire (Figure 3).

The level of assistance required to complete the PFFS-M was recorded by the principal investigator for all participants. This level was defined using a 3-point scale in which 0 indicated no assistance required, 1 indicated minimal assistance using verbal prompts and 2 indicated heavy assistance in which verbal descriptions were required for each level of the domains assessed.

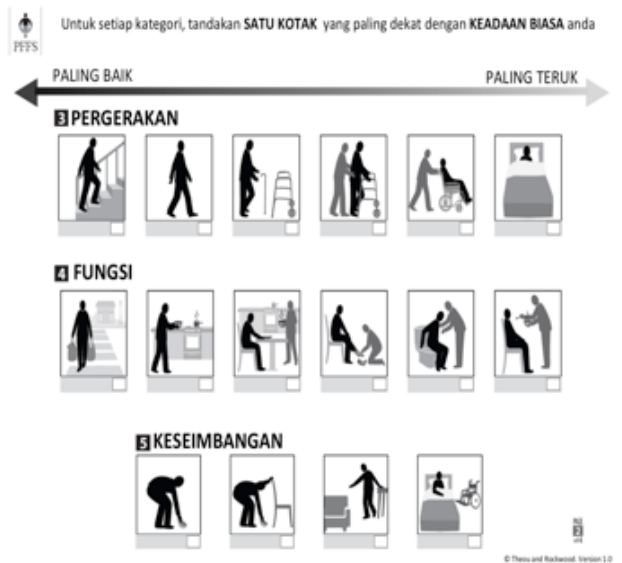

Figure 2. Pictorial Fit-Frail Scale Malay-Version (PFFS-M)

$\phi$

paung BaiK

6 PERGAULAN SOSIAL

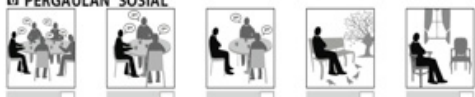

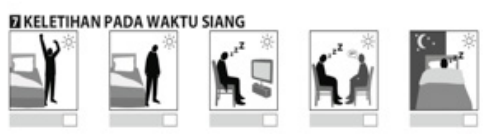

DDAYA INGATAN DAN PEMIKIRAN $\phi$

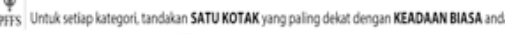

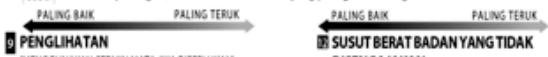
(O) (O) DISENGAKAN 11

II PENDENGaran ititit it ift

MKEBAKTAN

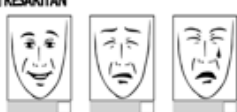

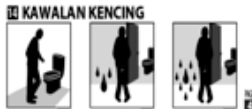

Figure 3. Acceptability questionnaire

Please give us your overall opinion about the scale by marking an $X$ in one of the boxes indicating your degree of agreement or disagreement with the following statements.

\begin{tabular}{ll|l|l|l|l|l} 
& & $\begin{array}{c}\text { Strongly } \\
\text { Agree }\end{array}$ & Agree & $\begin{array}{c}\text { Neither } \\
\text { Agree or } \\
\text { Disagree }\end{array}$ & Disagree & $\begin{array}{c}\text { Strongly } \\
\text { Disagree }\end{array}$ \\
\cline { 5 - 6 } 2 & The instructions of the scale were clear & & & & & \\
\hline $3 \quad$ The pictures were easy to understand & & & & & \\
\hline $4 \quad$ The picture size was appropriate & & & & & \\
\hline $5 \quad \begin{array}{l}\text { Pictures in each domain are appropriate } \\
\text { for each titles }\end{array}$ & & & & & \\
\hline
\end{tabular}




\section{Statistical Analysis}

Data collected was entered into IBM SPSS version 24. Appropriate descriptive statistics were used to summarize participants' baseline characteristics. Descriptive data was presented as mean and standard deviations (SDs) for normally distributed data or as medians and interquartile ranges (IQR25-IQR75) for asymmetric distributions, and categorical data was presented as proportion (\%). Scores agreement were defined as having the same score (excellent score agreement) or +1 and -1 scores (good score agreement) for each domain between assessors (patient versus caregiver and among healthcare professionals), and the level of agreement was presented as number of scores agreed over total responses for each domain in percentage. The main focus was to determine the level of agreement between both patients and their caregivers when assessing the patients' health state using the pictorial scale and among healthcare professional categories on the health domains represented by pictures in the scale based on the clinical vignette provided. The doctors' responses were used as references for comparison with responses from the nurses and healthcare assistants for agreement levels of the scale, with the assumption that doctors were better at assessing frailty.

\section{Results \\ Statistical Analysis}

There were minor ambiguities and discrepancies between the two backward translation versions (Back-translations 1 and 2) and between both backward translations and the original PFFS for 5 of 14 health domains: mobility, social connections, memory and thinking, pain and bladder control. These were resolved after critical consideration of the frailty concepts and attainment of semantic, conceptual equivalence between the original English PFFS and the PFFS-M in the Malaysian cultural setting (Table 1).

Table 1: Translation of the headings in the PFFS to Malay and back to English, with a final consensus producing the heading in the PFFS-M

\begin{tabular}{|c|c|c|c|c|c|}
\hline & $\begin{array}{l}\text { Original English } \\
\text { PFFS }\end{array}$ & $\begin{array}{l}\text { Forward } \\
\text { Translation } \\
\text { Consensus }\end{array}$ & $\begin{array}{l}\text { Backward } \\
\text { Translation } \\
\text { (Translator 1) }\end{array}$ & $\begin{array}{l}\text { Backward } \\
\text { Translation } \\
\text { (Translator 2) }\end{array}$ & $\begin{array}{l}\text { PFFS-M } \\
\text { (Final } \\
\text { Consensus) }\end{array}$ \\
\hline 1 & Mood & Mood & Mood & Mood & Mood \\
\hline 2 & $\begin{array}{l}\text { Number of } \\
\text { medications }\end{array}$ & Bilangan ubat & $\begin{array}{l}\text { Number of } \\
\text { medications }\end{array}$ & $\begin{array}{l}\text { Number of } \\
\text { medications }\end{array}$ & Bilangan ubat \\
\hline 3 & Mobility & Pergerakan & Movements & Mobility & $\begin{array}{l}\text { Keupayaan } \\
\text { bergerak }\end{array}$ \\
\hline 4 & Function & Fungsi & Function & Function & Tahap Kefungsian \\
\hline 5 & Balance & Keseimbangan & Balance & Balance & Keseimbangan \\
\hline 6 & $\begin{array}{l}\text { Social } \\
\text { connections }\end{array}$ & Pergaulan sosial & Social activities & Social interactions & Pergaulan sosial \\
\hline 7 & Daytime tiredness & $\begin{array}{l}\text { Keletihan pada } \\
\text { waktu siang }\end{array}$ & Daytime fatigue & Daytime tiredness & $\begin{array}{l}\text { Keletihan pada } \\
\text { waktu siang }\end{array}$ \\
\hline 8 & $\begin{array}{l}\text { Memory and } \\
\text { thinking }\end{array}$ & $\begin{array}{l}\text { Daya ingatan dan } \\
\text { pemikiran }\end{array}$ & $\begin{array}{l}\text { Memory and } \\
\text { thinking }\end{array}$ & $\begin{array}{l}\text { Memory and } \\
\text { Cognition }\end{array}$ & $\begin{array}{l}\text { Daya ingatan dan } \\
\text { pemikiran }\end{array}$ \\
\hline 9 & Vision & Penglihatan & Vision & Vision & Penglihatan \\
\hline 10 & Hearing & Pendengaran & Hearing & Hearing & Pendengaran \\
\hline 11 & Pain & Kesakitan & Illness & Pain & Tahap Kesakitan \\
\hline 12 & $\begin{array}{l}\text { Unintentional } \\
\text { Weight loss }\end{array}$ & $\begin{array}{l}\text { Susut berat } \\
\text { badan yang tidak } \\
\text { disengajakan }\end{array}$ & $\begin{array}{l}\text { Unintentional } \\
\text { weight loss }\end{array}$ & $\begin{array}{l}\text { Unintentional } \\
\text { weight loss }\end{array}$ & $\begin{array}{l}\text { Susut berat } \\
\text { badan yang tidak } \\
\text { disengajakan }\end{array}$ \\
\hline 13 & Aggression & Agresi & Aggression & Aggression & $\begin{array}{l}\text { Tingkahlaku } \\
\text { agresif }\end{array}$ \\
\hline 14 & Bladder control & $\begin{array}{l}\text { Kawalan pundi } \\
\text { kencing }\end{array}$ & Bladder control & Continence & Kawalan kencing \\
\hline
\end{tabular}




\section{Pilot and Feasibility Testing}

A total of 95 participants completed the PFFS-M: 20 patients, 20 caregivers for these patients, 16 healthcare assistants, 17 nurses and 22 doctors. The participants were multiethnic with $52.4 \%$ Malay, $21.9 \%$ indigenous (Iban, Bidayuh, orang Ulu, Melanau), $15.9 \%$ Chinese and 9.8\% Indian.

Table 2: Frailty Level by Patient Characteristics

\section{Patients and Their Caregivers}

The majority of the patients were aged between 60 and 75 years $(70 \%)$, and $60 \%$ were female. The PFFS and FI scores were higher in females, as age increased, and as overall health status declined (Table 2).

\begin{tabular}{|c|c|c|}
\hline Patient Characteristics $(n=20)$ & PFFS-M Scores Mean (SD) & FI Mean (SD) \\
\hline \multicolumn{3}{|l|}{ Gender } \\
\hline Male & $8.75(0.12)$ & $0.20(0.13)$ \\
\hline Female & $10.00(5.34)$ & $0.23(0.12)$ \\
\hline \multicolumn{3}{|l|}{ Age } \\
\hline$<65$ & $9.03(5.75)$ & $0.21(0.13)$ \\
\hline $65-74$ & $10.73(6.88)$ & $0.25(0.16)$ \\
\hline $75-84$ & $11.77(3.63)$ & $0.27(0.08)$ \\
\hline$>84$ & $13.75(0.96)$ & $0.32(0.02)$ \\
\hline \multicolumn{3}{|l|}{ Overall health status } \\
\hline Very good & $8.75(5.63)$ & $0.20(0.13)$ \\
\hline Good & $9.60(5.46)$ & $0.22(0.13)$ \\
\hline *Fair & $14.00(0)$ & $0.33(0)$ \\
\hline \multicolumn{3}{|l|}{$\begin{array}{l}\text { Health status compared } \\
\text { to others of the same age }\end{array}$} \\
\hline Much better & $3.00(0)$ & $0.07(0)$ \\
\hline Slightly better & $9.88(3.91)$ & $0.23(0.09)$ \\
\hline Neither & $9.33(6.19)$ & $0.22(0.14)$ \\
\hline Slightly worse & $7.67(6.03)$ & $0.18(0.14)$ \\
\hline${ }^{*}$ Much worse & $19.00(0)$ & $0.44(0)$ \\
\hline
\end{tabular}

*Data from only one patient

All caregivers who participated in the pilot study were family members of the patients, mostly aged below 65 years (45\%), and 65\% were female. The patients themselves reported lower PFFS-M scores than their caregivers provided. The mean PFFS and FI scores by the patients were $9.55(\mathrm{SD}=5.22)$ and $0.22(\mathrm{SD}$ $=0.12)$, respectively, compared to $11.7(\mathrm{SD}=$ $6.03)$ and $0.24(\mathrm{SD}=0.14)$ by the caregivers (table not shown).

Level of Assistance for Completion of PFFS-M for Patients and Caregivers

The majority of patients had required assistance to complete the scale (76.5\%), where $58.8 \%$ were minimally assisted and $17.7 \%$ were heavily assisted. Most of the caregivers (82.4\%) were able to complete the PFFS-M without assistance, and the remainder required minimal assistance (table not shown).

\section{Score Agreement Between Patients and Their Caregivers}

Overall, $66.7 \%$ to $94.4 \%$ of the patients and their caregivers had good score agreement for every domain in the scale. The lowest percentage for good score agreement was in the hearing domain (Table 3). 
Table 3: Scoring Agreement Between Patients and Their Caregivers

\begin{tabular}{lccc}
$\mathbf{Q}$ & Domain & $\begin{array}{c}\text { Excellent Score } \\
\text { Agreement }\end{array}$ & $\begin{array}{c}\text { Good Score } \\
\text { Agreement }\end{array}$ \\
\hline 1 & Mood & $38.9 \%$ & $88.9 \%$ \\
\hline 2 & Number of medications & $61.1 \%$ & $94.4 \%$ \\
\hline 3 & Mobility & $61.1 \%$ & $88.9 \%$ \\
\hline 4 & Function & $61.1 \%$ & $88.9 \%$ \\
\hline 5 & Balance & $61.1 \%$ & $72.2 \%$ \\
\hline 7 & Social connections & $44.4 \%$ & $72.2 \%$ \\
\hline 9 & Daytime tiredness & $77.8 \%$ & $88.9 \%$ \\
\hline 10 & Memory and thinking & $55.6 \%$ & $94.4 \%$ \\
\hline 11 & Vision & $33.3 \%$ & $88.9 \%$ \\
\hline 12 & Hearing & $38.9 \%$ & $66.7 \%$ \\
\hline 13 & Pain & $33.3 \%$ & $94.4 \%$ \\
\hline 14 & Unintentional weight loss & $55.6 \%$ & $88.9 \%$ \\
\hline & Aggression & $72.2 \%$ & $94.4 \%$ \\
\hline
\end{tabular}

Acceptability of the PFFS-M to Patients and Caregivers

The majority of the respondents had agreed that the instructions on the scale were clear (67.5\%), font and picture sizes were appropriate $(80 \%$ and $77.5 \%$, respectively), pictures were easily understood $(77.5 \%)$ and the domains' titles were appropriate for the pictures in each domain $(77.5 \%)$.

Verbal feedback on the scale by patients and caregivers were generally positive. Examples of feedback from the patients include the following: 'The pictures are big and clear. I didn't need my reading glasses.' 'I can understand most of the pictures easily, but some pictures, such as for memory and cognition and social connections, needed a little explanation.' II did not have any formal education, so I couldn't read the words, but I can understand the pictures.' An example of feedback from one of the caregivers was 'I don't like wordy questionnaires, but this is good. I just see the pictures and tick. Easy.' Therefore, no modifications were made to the tool based on the overall feedback from the patients and caregivers.

\section{Healthcare Professionals}

Fifty-five healthcare professionals completed the PFFS-M based on a clinical vignette given. The mean PFFS-M scores and FI for the clinical vignette were $14.44(\mathrm{SD}=5.89)$ and $0.34(\mathrm{SD}=0.14)$ by healthcare assistants, were $10.3(\mathrm{SD}=4.09)$ and $0.24(\mathrm{SD}=0.09)$ by nurses and were $9.35(\mathrm{SD}=3.98)$ and $0.21(\mathrm{SD}=0.09)$ by doctors, respectively (table not shown).

Level of Assistance Required for Completion of PFFS-M Among Healthcare Professionals

Majority of the healthcare professionals across all categories were able to complete the PFFS-M with no assistance $(78.8 \%)$. The remaining $21.2 \%$ of healthcare professionals had required minimal help with completing the scale, with almost half were the healthcare assistants (45.5\%), followed by doctors (36.4\%) and nurses (18.2\%) (table not shown).

\section{Score Agreement Between Healthcare Professionals} The responses from the doctors were used as reference points in comparing score agreement among healthcare professional categories for each domain, with the assumption that doctors are better at assessing frailty. Overall, $75.9 \%$ to $98.9 \%$ of the healthcare respondents had the same or $+1 /-1$ scores for every domain in the scale. The lowest percentage for score agreement was in the social connections' domain. When compared to the scores by the doctors, there was better agreement with the scores by the nurses than the scores by the healthcare assistants (Table 4). 
Table 4: Scoring Agreement Between Doctors and Other Healthcare Professional Raters in PFFS-M Clinical Vignette Scoring

\begin{tabular}{|c|c|c|c|c|c|}
\hline \multirow[b]{2}{*}{$\mathbf{Q}$} & \multirow{2}{*}{ Domain } & \multicolumn{2}{|c|}{ Doctors and Nurses } & \multicolumn{2}{|c|}{ Doctors and Healthcare Assistants } \\
\hline & & $\begin{array}{l}\text { Excellent Score } \\
\text { Agreement }\end{array}$ & $\begin{array}{l}\text { Good Score } \\
\text { Agreement }\end{array}$ & $\begin{array}{l}\text { Excellent Score } \\
\text { Agreement }\end{array}$ & $\begin{array}{l}\text { Good Score } \\
\text { Agreement }\end{array}$ \\
\hline 1 & Mood & $31.6 \%$ & $89.5 \%$ & $31.3 \%$ & $56.3 \%$ \\
\hline 2 & $\begin{array}{l}\text { Number of } \\
\text { medications }\end{array}$ & $33.3 \%$ & $89.7 \%$ & $31.3 \%$ & $56.3 \%$ \\
\hline 3 & Mobility & $53.8 \%$ & $100 \%$ & $25.0 \%$ & $87.5 \%$ \\
\hline 4 & Function & $76.9 \%$ & $97.4 \%$ & $37.5 \%$ & $87.5 \%$ \\
\hline 5 & Balance & $56.4 \%$ & $100 \%$ & $50.0 \%$ & $87.5 \%$ \\
\hline 6 & Social connections & $61.5 \%$ & $84.6 \%$ & $18.8 \%$ & $62.5 \%$ \\
\hline 7 & Daytime tiredness & $66.7 \%$ & $100 \%$ & $62.5 \%$ & $87.5 \%$ \\
\hline 8 & $\begin{array}{l}\text { Memory and } \\
\text { thinking }\end{array}$ & $61.5 \%$ & $87.2 \%$ & $37.5 \%$ & $68.8 \%$ \\
\hline 9 & Vision & $56.4 \%$ & $97.4 \%$ & $25.0 \%$ & $100 \%$ \\
\hline 10 & Hearing & $94.9 \%$ & $97.4 \%$ & $68.8 \%$ & $87.5 \%$ \\
\hline 11 & Pain & $59.0 \%$ & $92.3 \%$ & $37.5 \%$ & $87.5 \%$ \\
\hline 12 & $\begin{array}{l}\text { Unintentional } \\
\text { weight loss }\end{array}$ & $56.4 \%$ & $92.3 \%$ & $43.8 \%$ & $81.3 \%$ \\
\hline 13 & Aggression & $97.4 \%$ & $100 \%$ & $81.3 \%$ & $93.8 \%$ \\
\hline 14 & Bladder control & $94.9 \%$ & $100 \%$ & $62.5 \%$ & $82.3 \%$ \\
\hline
\end{tabular}

Acceptability of the PFFS-M to Healthcare Professionals

All healthcare professional respondents had provided their overall feedback on the scale using the acceptability questionnaire, and the majority agreed that the instructions on the scale were clear (87\%), the font and picture sizes were appropriate $(92.7 \%$ and $94.5 \%$, respectively), pictures were easily understood $(81.8 \%)$ and the domains' titles were appropriate for the pictures in each domain (92.8\%). Verbal feedback on the scale by healthcare professionals was generally positive. Examples of this feedback include the following: 'This is an easy, simple and quick way to assess an elderly in our busy clinic.' 'This is a very practical checklist, so I won't miss any important assessments in an older person.' 'Only pictures and little words. Easy! I will definitely use this tool in my clinical practice.' Therefore, no modifications were made to the tool based on the overall feedback from the healthcare professionals.

\section{Discussion}

The PFFS is a simple tool for frailty screening that uses visual prompts to assess a person's frailty levels. In this study, the English version was successfully translated into Malay using a rigorous multistep process. The translated Malay version of the PFFS was deemed to have semantic, conceptual equivalence to the original English version; this is important because, in the translation of an Englishlanguage scale into Malay, a Malay word may have multiple inferences and multiple Malay terms may share a single meaning. The minor discrepancies between the backward translations and the English version of the PFFS for mobility, memory and thinking, social connections and bladder control were easily resolved after consideration of the frailty concepts. The translation of the PFFS into Malay was reasonable, and the terms used in this scale were culturally applicable in the Malaysian context. 
The PFFS-M was easy and practical to use; the majority of the participants were able to complete the scale independently, and the acceptability survey reported overall positive feedback from all participants in relation to appropriateness and understandability of the pictures, domain titles and instructions on the scale (67.5-94.5\%). However, the pilot study showed that many patients required assistance to complete the scale. We propose that, for the Malaysian context, the tool could be first completed by the patients themselves. If they have caregivers, the caregivers could assist with scale completion. However, healthcare professionals should still verify the scale completion and assist where required, particularly where there are discrepancies between the patients' or caregivers' assessments and the healthcare professionals' assessment because the latter may be able to assess frailty better than the patients themselves or the patients' caregivers can. Most important, all perspectives must be taken into consideration when making care plan decisions relating to a patient's frailty level; this suggested process would aid in the implementation of the tool in the busy primary care clinic settings commonly encountered in many Asian countries.

The percentages of good score agreement for every domain in the scale (having a similar or $+1 /-1$ score) were high between the patients and their caregivers (66.7-94.4\%) as well as among the healthcare professional categories (75.9-98.9\%). Similar findings were reported in Canada and the UK, with percentage score agreements between $66 \%$ to $95 \%$ when tested among patients, caregivers and healthcare professionals. ${ }^{12}$ Therefore, the PFFS is widely understood, and interpretation of the visual images from different perspectives, including self-assessments by patients, assessments their caregivers and assessments among healthcare professional groups, were relatively similar. The PFFS is also potentially generalizable and feasible across differing cultural and linguistic settings.

Healthcare assistants are frontline staff members who are present across all public primary care settings in Malaysia. It was, however, observed that the healthcare assistants required some assistance to complete the scale (45.5\%) and had lower agreement scores than the nurses provided when compared with the doctors' assessments. This observation showed that healthcare professionals of varying skills have different levels of understanding of the PFFS-M and consequently their frailty assessments of the patients using the scale differed. A further outcome from this research has been the development of a training module for all healthcare professional raters aimed at improving their understanding of the domains within the scale and how to score the tool.

Limitations of this study included the limited testing of this scale, namely, in primary care settings in Malaysia; investigation of this screening tool in other care settings, such as hospitals and long-term care facilities, may bolster the effectiveness of the tool further or identify its potential weaknesses. Nevertheless, the strength of this study was its broad geographic span, with data collected from both peninsular Malaysia and Borneo as well as from both urban centres and rural areas.

To conclude, the Malaysian population readily accepted the PFFS-M, which appears feasible for use among patients, caregivers and healthcare providers throughout Malaysia. The next phase involves testing of the psychometric properties of the scale, including inter-rater and test-retest reliability, and construct and predictive validity. The availability of a valid tool with clinical utility would facilitate screening for frailty risk in Malaysia and support early intervention to prevent or manage frailty more effectively.

\section{Acknowledgements}

This study was funded by the Ministry of Health Malaysia Research Grant (NMRR 17-543-348840. The authors would like to acknowledge all the staff of the publicprimary care clinics and district/divisional health offices of the study sites involved. This research was also conducted in collaboration with the Australian National Health and Medical Research Council (NHMRC) Centre of Research Excellence in Frailty and Healthy Ageing.

\section{Conflict of Interest Disclosures}

The authors declare that no conflicts of interest exist. 


\section{How does this paper make a difference to general practice?}

- This study constitutes original research on the translation of a newly developed frailty screening tool for specific use in Malaysia.

- The Malay version of the Pictorial Fit-Frail Scale (PFFS-M) is now available for further testing.

- The PFFS-M can be potentially used as a frailty screening tool in clinical settings throughout Malaysia.

\section{References}

1. Kinsella K, Phillips DR. Global aging: The challenge of success. Popul Bull. 2005;60(1):1-44.

2. Draft report of the main committee world assembly on ageing Vienna, 26 July - 6 August, 1982. Aust J Ageing. 1982;1(4):15-31.

3. Tey NP, Siraj SB, Kamaruzzaman SBB, et al. Aging in multi-ethnic Malaysia. Gerontologist. 2016;56(4):603-609.

4. Sathasivam J, Kamaruzzaman SB, Hairi F, et al. Frail elders in an urban district setting in Malaysia: Multidimensional frailty and its correlates. Asia Pac J Public Health. 2015 Nov;27(8 Suppl):52S-61S.

5. Clegg A, Young J, Iliffe $S$, et al. Frailty in elderly people. Lancet. 2013; 381(9868): 752-762.

6. Fried LP, Tangen CM, Walston J, et al. Frailty in older adults: Evidence for a phenotype. J Gerontol Med Sci. 2001;56(3):146-157.
7. Song X, Mitnitski AA, Rockwood K, et al. Prevalence and 10-year outcomes of frailty in older adults in relation to deficit accumulation. J Am Geriatr Soc. 2010;58(4):681-687.

8. Bleijenberg N, Drubbel I, Neslo RE, et al. Cost-effectiveness of a proactive primary care program for frail older people: A clusterrandomized controlled trial. J Am Med Dir Assoc. 2017;18(12):1029-1036.

9. Bleijenberg N, Drubbel I, Schuurmans MJ, et al. Effectiveness of a proactive primary care program on preserving daily functioning of older people: A cluster randomized controlled trial. J Am Geriatr Soc. 2016;64(9):1779-1788.

10. Jaafar S, Noh KM, Muttalib KA, et al. Malaysia health system review. Vol 3. No.1. New Delhi: World Health Organization, regional office for the Western Pacific, 2013.
11. Quek D. The Malaysian health care system: A review. Presented at: Intensive workshop on health systems in transition; April 29 - 30, 2009; Kuala Lumpur; Malaysia.

12. Theou O, Andrew M, Ahip S, et al. The pictorial fit-frail scale: Developing a visual scale to assess frailty. Can Geriatr J. 2019;22(2):64-74.

13. Mcgarrigle L, Squires E, Wallace LMK, et al. Investigating the feasibility and reliability of the pictorial fit-frail scale. Age Ageing. 2019;48(6):832-837.

14. Wallace LMK, McGarrigle L, Rockwood K, et al. Validation of the pictorial fit-frail scale in a memory clinic setting. Int Psychogeriatrics. 2019:1-10.

15. Kamus Pelajar Bahasa Malaysia. Cet. 1. Kuala Lumpur: Dewan Bahasa Dan Pustaka, Kementerian Pelajaran Malaysia; 1987. 